\title{
Clinical Usefulness of Estimated Speaking Fundamental Frequency Using the Voice and Speech Range Profiles in Voice Disorders
}

\author{
Seung Jin Lee ${ }^{\mathrm{a}, \mathrm{b}}$, Jaeock Kim ${ }^{\mathrm{c}}$ \\ ${ }^{a}$ Department of Otorhinolaryngology, Yonsei University College of Medicine, Seoul, Korea \\ ${ }^{b}$ The Institute of Logopedics and Phoniatrics, Department of Otorhinolaryngology, Gangnam Severance Hospital, Seoul, Korea \\ 'Division of Speech Pathology Education, Graduate School of Education, Kangnam University, Yongin, Korea
}

Correspondence: Seung Jin Lee, PhD Department of Otorhinolaryngology, Yonsei University College of Medicine, Gangnam Severance Hospital, 211 Eonju-ro, Gangnam-gu, Seoul 06273, Korea

Tel: $+82-2-2019-2589$

Fax: $+82-2-3463-4750$

E-mail: slplee@yonsei.ac.kr

Received: April 16, 2020

Revised: May 13, 2020

Accepted: May 18, 2020

This work was supported by the Ministry of Education of the Republic of Korea and the National Research Foundation of Korea (NRF2018S1A5A2A03032902)
Objectives: The purpose of the study was to determine whether estimated speaking fundamental frequency (ESFO) using the voice and speech range profiles and differences

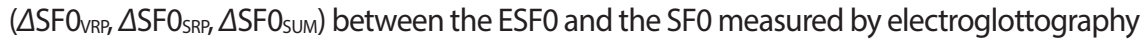
( $\left.\mathrm{SFO}_{\mathrm{EGG}}\right)$ differ according to the presence of voice disorders and gender. Moreover, correlation between $\mathrm{SFO}_{\mathrm{EGG}}$ and ESFO measures, and between the $\mathrm{G}$ of the GRBAS scale and $\triangle \mathrm{SFO}$ measures was explored. Clinical usefulness of $\triangle \mathrm{SFO}$ as a screening tool was also explored. Methods: A total of 85 patients with voice disorders and 85 normal adults participated in the study. For each participant, $\mathrm{SFO}_{\mathrm{EGG}}$ was measured using a passage-reading task and electroglottography. Maximum/minimum pitch, pitch range in $\mathrm{Hz}$ and semitone were mea-

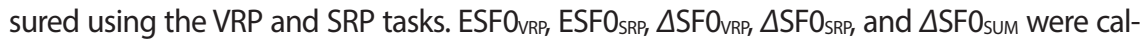
culated. Results: Significant difference between groups in the ESFOSRP was found only for males. Patient group's $\triangle S F 0$ measures were higher than the normal group. Strong positive correlation between the $\mathrm{SFO}_{\mathrm{EGG}}$ and the ESF0 measures was found. There was weak positive correlation between the $\mathrm{G}$ and $\triangle \mathrm{SFO}$ measures. The AUC of the $\triangle \mathrm{SFO} \mathrm{VRP}_{1}, \triangle \mathrm{SFO} \mathrm{SRP}_{1}, \triangle \mathrm{SFO} 0_{\mathrm{SUM}}$ was $.690, .673, .771$, the cutoff score $10.867,10.347,17.777$, respectively. The AUC of the $\triangle \mathrm{SFO}$ SUm was higher than those of the $\triangle \mathrm{SFO} \mathrm{VRP}_{\mathrm{RP}}$ and $\triangle \mathrm{SFO} \mathrm{SRP}_{\mathrm{SP}}$. Conclusion: Results indicated that the $\triangle \mathrm{SFO}$ showed potential as an objective index for screening voice disorders, especially for those characterized by pitch change. The $\triangle \mathrm{SFO}$ could enhance the clinical usefulness of the VRP and SRP.

Keywords: Voice disorders, Estimated speaking fundamental frequency (ESF0), Differences in speaking fundamental frequency $(\triangle \mathrm{SF} 0)$, Voice range profile, Speech range profile
후두나 성대의 병변은 성대의 질량, 길이, 긴장도 등에 영향을 주 며, 이는 다시금 후두의 공기역학적 기능에 영향을 미쳐 발성 가능 한 음역대, 즉 발성 시 주파수와 강도의 범위를 제한하게 된다(Ma \& Yiu, 2011). 따라서 어떠한 병변이 발성 능력(vocal capacity)에 미 치는 영향을 역동적으로 평가하기 위해서는 합리적인 조건 하에서 생리학적인 기능의 한계에 이르기까지 발성 능력을 검사하여야 한 다. 음성 범위 프로파일(voice range profile, VRP)은 음향학적인 평 가의 하나이며, 특정 대상자의 음역대를 객관적으로 측정할 수 있
는 검사이다. 이를 통해 측정한 양적 측정치들은 가창 훈련 시 출발 점을 제시하거나 훈련 성과를 측정하는 데 활용될 수 있고, 음성장 애의 진단에도 이용되며, 음성치료를 통한 진전 정도를 평가하는 데에도 유용하다(Sataloff, 2005; Siupsinskiene \& Lycke, 2011). Patel 등(2018)은 최근 American Speech-Language-Hearing Association (ASHA) 전문가 패널의 논의를 통해 발성 기능의 기기적 평가 를 위한 프로토콜의 핵심 과제와 측정치들을 제시하였는데, 여기 에서도 이러한 음역대를 측정하는 절차를 필수적으로 포함할 것을 
권고하였다. 즉 발성 음압(vocal sound pressure level)과 발성 주파 수(vocal frequency)의 최소 및 최대치를 측정할 것을 권고하였으 며, 이때 임상에서의 간단한 시행을 위해 가장 큰 소리와작은 소리, 가장 높은 음도와 낮은 음도를 1초 동안 유지하도록 하는 과제를 제안하기도 하였다(Patel et al., 2018).

$\mathrm{VRP}$ 는 이보다 훨씬 다양한 검사 수행방식을 이용하여 이루어 질 수 있는데, 예컨대 가장 저음에서 고음에 이르기까지, 또 각 반 음(semitone)에서 개별 음 자극을 참고로 하여 가장 작은 음에서 큰 음에 이르기까지 각각 음도와 크기의 범위를 기록함으로써 전 체 포네토그램(full phonetogram)을 확립하는 방법이 있다(Jung, Choi, \& Choi, 2019; Kim et al., 2009). 다른 연구에서는 시간적 효 율성을 제고하기 위하여 남성의 경우 7 개의 음, 여성의 경우 넓은 음역대를 반영하여 9 개의 음에서 강도의 범위를 측정하는 축약된 VRP 방법이 제시되기도 하였다(Jung et al., 2019). 다른 연구들에 서는 여러 번의 활창을 통해 음역대를 확립하거나(Sanchez, Oates, Dacakis, \& Holmberg, 2014), 편안한 음도와 크기에서 출발하여 가 장 낮고 작은 소리까지 계단식으로 활창(decrescendo)한 뒤, 다시 첫 음에서 가장 제일 크고 높은 음에 이르기까지 활창(crescendo) 하는 방식을 활용하기도 하였는데(Kim \& Lee, 2019), 이는 정상인 의 VRP의 경우 대개 주파수와 강도가 비례하여 포네토그램이 우 상향으로 기울어진 타원 모양이 된다는 점(Lee \& Kim, 2019; Ma \& $\mathrm{Yiu}, 2011)$ 에 근거하고 있다. 다양한 방식의 VRP는 대상자의 발성 능력을 평가하고, 그 변화를 추적하며, 대상자에게 피드백을 제공 함으로써 임상에서 유용하게 활용되어 오고 있다. 구체적으로 살 펴보면, VRP에 관련된 다양한 연구들을 살펴보았을 때, 음성장애 환자의 VRP 범위가 정상 음성을 가진 정상군에 비해 감소한다거 나, Lax Vox 등 특정 치료기법을 사용한 음성치료 후 증가한다는 연구 등 여러 선행연구들이 VRP가 지닌 진단 및 중재효과 평가 도 구로서의 가능성을 지지하고 있다(Ma \& Yiu, 2006; Ma et al., 2007; Mailänder, Mühre, \& Barsties, 2017; Meerschman et al., 2017; Wuyts et al., 2000). 그러나 음성장애를 조기에 선별하고 중재하는 데에 있 어 VRP에서 측정되는 다양한 변수들이 구체적으로 어떤 기여를 할 수 있는지, 즉 정상적인 음성으로부터 병리적인 음성을 구분하 는 변수와 그 기준치가 어떠한지에 대해서는 연구가 매우 부족한 실정이다.

VRP는 대개 모음 발성을 통해 평가되는데, 이는 우리가 실제 발 화를 산출할 때의 다양한 발성 양식이 온전히 반영된 것으로 보기 어렵다는 한계를 불러오게 된다. 이러한 맥락에서 여러 연구들에 서는 발화 범위 프로파일(speech range profile, SRP)을 통해 기능 적 말 산출 능력을 평가하거나, 중재 전후의 음성 변화를 살펴 보는
방법으로 활용해오고 있다(Berg et al., 2017; D’Alatri \& Marchese, 2014; dos Santos, de Menezes Borrego, \& Behlau, 2015; Kim \& Lee, 2019; Lee \& Kim, 2019; Ma et al., 2007). 발화를 이용하는 특성상, $\mathrm{SRP}$ 는 자동구어에 해당되는 숫자세기를 비롯하여 독백, 문장 및 문단 읽기, 노래하기, 소리지르기 등 다양한 과제와 자료를 이용하 여 시행될 수 있다. 예컨대 Kim과 Lee (2019)는 서술문을 비롯하여 의문문, 큰 소리 지르기가 포함된 문단 수준의 새로운 SRP 발화과 제('불이야' 문단)를 개발하여 정상인에서 주파수 및 강도 측정치 를 제시하였다. Lee와 Kim (2019)은 이와는 또 다른 맥락으로 기존 에 한국의 음성장애 임상 현장에서 널리 이용되는 표준문단인 '가 을' 문단의 첫 문장을 이용하여 간단하게 시행할 수 있는 방법을 제 시하고, 이에 따른 주파수와 강도 측정치를 제시하기도 하였다. $\mathrm{SRP}$ 또한 VRP와 마찬가지로, 주파수와 강도 관련 변수에 있어 음 성장애를 지닌 환자군과 정상 음성을 지닌 정상군 간의 차이를 보 였다(D'Alatri \& Marchese, 2014). 또 다른 연구에서는 VRP의 면 적, 최대 및 최소 강도와 SRP의 SF0 범위, 그리고 강도의 최댓값을 이용하여 각각 음성장애 여부를 $95 \%$ 이상 정확하게 예측할 수 있 다고 보고하였다(Ma et al., 2007). 이와 같은 연구결과들은 VRP와 $\mathrm{SRP}$ 의 측정치들이 음성장애를 선별하는 검사도구로써 사용될 가 능성을 시사하는 것이라고도 볼 수 있다. 다만 우리말 자료의 SRP 를 통해 이러한 유용성을 확인하고, 다양하고 구체적인 방법을 제 시하는 일이 시급하다 할수 있다.

앞서 언급한 Lee와 Kim (2019)의 연구에서는 정상 성인을 대상 으로 비교적 간단한 형태의 VRP와 SRP를 적용하였다. 이를 통해 측정한 발성 주파수와 관련된 변수들을 이용하여, 문단 읽기 과제 수행 시 전기성문파형검사(electroglottography, EGG)로 측정한 평 균 발화 기본주파수(speaking fundamental frequency, SF0)를 예 측할 수 있는 두 개의 모형을 구축하였다. 그리고 VRP와 SRP의 각 모형을 통해 예측된 SF0를 추정 발화 기본주파수(estimated SF0, $\mathrm{ESF}_{\mathrm{VRP}}$ 와 $\mathrm{ESF}_{\mathrm{SRP}}$ 로 명명하였다. 또한 정상인에서 $\mathrm{SF}_{\mathrm{EGG}}$ 와 $\mathrm{ESF} 0$ 간 차이의 절댓값, 즉 발화 기본주파수 차이(differences in SF0, $\Delta \mathrm{SF}_{\mathrm{VRP}}$ 와 $\left.\Delta \mathrm{SF}_{\mathrm{SRP}}\right)$ 를 계산하고, 두 $\Delta \mathrm{SF} 0$ 의 합계 $\left(\Delta \mathrm{SF} 0_{\mathrm{SUM}}\right)$ 또한 계산하였다. 이를 통해 정상 성인에서 성별에 따른 각 변수의 자료 를 제시하였으며, $\Delta \mathrm{SF}_{\mathrm{VRP}}$ 와 $\Delta \mathrm{SF} 0_{\mathrm{SRP}}, \Delta \mathrm{SF}_{\mathrm{SUM}}$ 에 있어 유의한 성별 차가 없음을 확인하였다. 그러나 음성장애를 가진 환자군과 정상 군 간 $\Delta \mathrm{SF}_{\mathrm{VRP}}$ 와 $\Delta \mathrm{SF}_{\mathrm{SRP}}, \Delta \mathrm{SF} 0_{\mathrm{SUM}}$ 의 차이를 보이는지, 그리고 만 약 차이가 있다면 음성장애 선별 검사도구로서 활용될 수 있을 만 한 잠재력을 가지고 있는지에 대해서는 연구된 바가 없는 실정이다. 만약 이러한 임상적인 유용성이 확인될 수 있다면, 기존에 활용되 는 VRP와 SRP 과제들, 새로이 개발되고 있는 VRP와 SRP 프로토 
콜들과 더불어 상호보완적으로 평가의 목적에 따라 다양한 임상 적 활용이 가능할 것으로 기대된다.

따라서 본 연구에서는 음성장애를 지닌 환자군과 정상군의 집단 과 성별에 따른 $\Delta \mathrm{SF}_{\mathrm{VRP}}, \Delta \mathrm{SF} 0_{\mathrm{SRP}}, \Delta \mathrm{SF}_{\mathrm{SUM}}$ 의 차이가 있는지 확인하 고자 하였다. 또한 $\mathrm{SF}_{\mathrm{EGG}}, \mathrm{ESF}_{\mathrm{VRP}}, \mathrm{ESF} 0_{\mathrm{SRP}}$ 간 상관관계가 있는지, 그리고 세 가지의 $\triangle \mathrm{SF} 0$ 가 청지각적 평가를 통해 측정된 전반적 중 증도 평정치와 상관관계가 있는지를 알아보았다. 마지막으로 음성 장애에 대한 선별검사 도구로서의 유용성을 가지고 있는지 알아보 고, 환자군과 정상군 간의 구분을 위한 기준점(cutoff score)을 확인 하고자 하였다.

\section{연구방법}

\section{연구대상}

MedCalc 통계 소프트웨어 버전 19.1.7 (MedCalc Software Ltd., Ostend, Belgium; https://www.medcalc.org; 2020)를 이용하여 두 개의 수신자 조작 특성(receiver operating characteristic, ROC) 곡선 간의 비교를 위한 최소의 표본 수를 산정한 결과 대상자 수가 집단 별로 82명이었다(Significance $=0.05,1$-Power $=0.20$, Area under curve $=0.7 / 0.6$, correlation in positive and negative groups $=0.7$, Ratio of negative/positive samples $=1$ ). 따라서 대상자 수는 환자군 과 정상군 각 85 명으로 하였다.

환자군은 서울에 위치하고 있는 대학 병원 이비인후과 음성검사 실에 내원하여 이비인후과 전문의에게 음성장애 진단을 받은 음성 장애 환자 85명(남성 30명, 여성 55명, 연령 $36.06 \pm 11.86$ 세)이었다. 정상군은 환자군에 연령 $( \pm 3$ 세 이내)과 성별을 일치시킨 정상 음 성 사용자 85 명(남성 30 명, 여성 55명, 연령 $36.32 \pm 11.46$ 세)이었다. 두 집단 간 직업적 음성사용자(가수, 배우 등 엘리트 음성사용자와 교강사, 목사, 상담원 등 직업적 음성사용자)의 비율 $(p=.165)$ 과 연 령 $(t=.145, p=.885)$ 의 유의한 차이는 없었다. 대상자 중 음성장애 와 관련이 있을 수 있는 신경학적 병력이나 수술력, 최근 1 개월 내 흡연력이 보고된 자는 연구에서 제외되었다. 정상군에는 서울 지역 에 거주 중인 한국어 모국어 화자와 함께, 갑상선절제술(thyroidectomy) 시행 전의 음성검사를 위해 검사실에 내원한 대상자가 함께 포함되었다(Awan, Roy, \& Cohen, 2014).

정상군에 대해서는 다면적인 음성 평가를 통해 잠재적인 음성문 제를 가지고 있을 수 있는 대상자를 제외하고자 하였다. 이를 위해 면담을 통한 병력 청취, 문단 읽기 샘플에 대한 청지각적 평가, 자기 보고식 설문지를 이용한 심리측정적 평가, 구조적 병변을 배제하기 위한 후두 스트로보스코피를 시행하였다(Awan et al., 2014). 먼저
면담 시 최근 3 개월 이내 흡연력 혹은 감기 등의 증상으로 병원에 내원한 이력이 있는 자는 배제하였다. 청지각적 평가에서는 '가을' (Kim, 2012) 문단 읽기 시 GRBAS (Hirano, 1981) 척도를 이용하여 평정하였을 때 전반적인 중증도(Grade, $\mathrm{G})$ 가 1 이상 $(\mathrm{G}=1,2,3)$ 인 경우 제외되었다. 심리측정적 평가의 경우 정상군과 환자군을 나 누는 기준점이 제시되어 있는 설문지인 음성 활동 및 참여 프로파 일-한국판(Korean Version of the Voice Activity and Participation Profile, K-VAPP)의 총점이 14.5점 이상인 경우 제외되었다(Lee et al., 2016). 후두 스트로보스코피의 경우 이비인후과 전문의가 기질 적 음성장애를 유발할 수 있는 질환이 있다고 진단한 경우 연구에 서 제외되었다. 각 집단의 인구학적 정보와 환자군의 음성장애 진 단명에 대한 정보가 Table 1에 제시되어 있다.

Table 1. Demographic data of the participants

\begin{tabular}{|c|c|c|c|}
\hline Parameters & $\begin{array}{l}\text { Patient group } \\
\qquad(\mathrm{N}=85)\end{array}$ & $\begin{array}{l}\text { Normal group } \\
\qquad(\mathrm{N}=85)\end{array}$ & $p$-value \\
\hline \multicolumn{4}{|l|}{ Age (yr) } \\
\hline Range & $19-64$ & $19-61$ & \\
\hline $\mathrm{M}(\mathrm{SD})$ & $36.06(11.86)$ & $36.32(11.46)$ & .885 \\
\hline \multicolumn{4}{|l|}{ Gender [N (\%)] } \\
\hline Male & $30(35.3)$ & $30(35.3)$ & \\
\hline Female & $55(64.7)$ & $55(64.7)$ & 1.000 \\
\hline Professional voice user [N (\%)] & $43(50.6)$ & $33(38.8)$ & .165 \\
\hline G [M (SD)] & $2.35(0.62)$ & $0.43(0.18)$ & $<.001^{* * *}$ \\
\hline \multicolumn{4}{|l|}{ K-VAPP } \\
\hline Total score $(280)^{a}$ & $141.27(68.01)$ & $2.59(3.83)$ & $<.001^{* * *}$ \\
\hline ALS (100) & $47.42(25.65)$ & $1.21(2.29)$ & $<.001^{* * *}$ \\
\hline PRS (100) & $46.76(27.23)$ & $0.25(0.84)$ & $<.001^{* * *}$ \\
\hline Diagnosis of the patients [N (\%)] & & - & - \\
\hline Spasmodic dysphonia, adductor type & $15(17.6)$ & & \\
\hline Vocal polyp, unilateral & $14(16.5)$ & & \\
\hline Sulcus vocalis, bilateral & $12(14.1)$ & & \\
\hline Vocal fold palsy, unilateral & $8(9.4)$ & & \\
\hline Laryngopharyngeal reflux disease & $7(8.2)$ & & \\
\hline Intracordal cyst, unilateral & $5(5.9)$ & & \\
\hline Primary muscle tension dysphonia & $5(5.9)$ & & \\
\hline Vocal nodules, bilateral & $5(5.9)$ & & \\
\hline Reinke's edema & $5(5.9)$ & & \\
\hline Laryngeal papilloma & $3(3.5)$ & & \\
\hline Vocal fold leukoplakia & $2(2.4)$ & & \\
\hline Vocal fold scarring & $2(2.4)$ & & \\
\hline Contact granuloma & $1(1.2)$ & & \\
\hline Vocal fold paresis, unilateral & $1(1.2)$ & & \\
\hline
\end{tabular}

$\mathrm{M}=$ mean; $\mathrm{SD}=$ standard deviation; $\mathrm{G}=\mathrm{Grade}$ of the GRBAS scale; $\mathrm{K}-\mathrm{VAPP}=$ Korean version of the Voice Activity \& Participation Profile; ALS=Activity Limitation Score; PRS= Participation Restriction Score.

${ }^{\text {aC }}$ ut-off score $=14.5$.

${ }^{* * *} p<.001$. 


\section{연구절차}

녹음을 위한 기자재로는 Computerized Speech Lab (Model 4150B; KayPentax, Lincoln Park, NJ, USA; CSL)의 하드웨어(오디 오 인터페이스)와 Real-time EGG 하드웨어(Model 6103; KayPENTAX, Lincoln Park, NJ, USA), SM48 단일지향성 다이나믹 마이크 (SHURE, Niles, IL, USA)를 이용하였다. VRP와 SRP를 위한 소프 트웨어로는 CSL의 모듈 프로그램 중 하나인 Voice Range Profile (Model 4326; KayPENTAX, Lincoln Park, NJ, USA; VRP)를, 문단 읽기 샘플의 녹음에는 CSL 메인 프로그램(Model 4150B; KayPentax, Lincoln Park, NJ, USA)을, 문단 읽기 샘플의 EGG 분석에는 Real-time EGG 프로그램(Model 6103; KayPENTAX, Lincoln Park, NJ, USA)을 이용하였다. CSL 메인 프로그램을 이용한 녹음 시에는 채널 1에는 마이크를 통해 입력된 음향학적 신호가, 채널 2에는 EGG 하드웨어를 통해 입력된 EGG 신호가 기록되도록 하였는데, 이는 Real-time EGG 프로그램의 녹음 제한 시간이 1 분으로 되어 있어 전체 문단을 녹음하는데 불충분할 가능성이 높기 때문이었다.

구체적인 실험절차는 다음과 같다. 먼저 대상자로 하여금 조용 한 음성검사실 내에서 의자의 등받이에서 등을 뗀 채 허리를 펴고 바르게 착석하도록 하였다. 환경 소음은 실험 절차를 진행하는 동 안 소음 측정기(Voltcraft Datalogger 322; Conrad Electronic, Hirschau, Germany)를 통해 모니터링하여 $50 \mathrm{~dB}$ 이하로 유지하였다. 마이크는 대상자의 입으로부터 10센티미터 정도를 유지하면서, 벨 크로를 이용하여 갑상 연골의 패임(notch)이 있는 높이의 갑상연 골 양측 부위에 EGG의 전극을 부착시킨 후, 전체 '가을' 문단을 소 리 내어 읽도록 하여 녹음하였다. 이때 가족과 대화를 하듯이 자연 스러운 음도와 크기로 읽도록 안내하였다. VRP와 SRP의 경우 CSL 하드웨어의 Voice Range Profile Mode 버튼을 눌러 점등시킨 상태 에서 진행하였다. 먼저 SRP 과제에서는 녹음을 시작한 직후 '가을' 문단(Kim, 2012)의 첫 번째 문장인 '우리나라의 가을은 참으로 아 름답다.를 편안한 음도와 크기로 읽도록 한 후 VRP 플롯을 저장하 였다. VRP 과제는 모음/아/를 활창(gliding)하는 과제를 통하여 진 성구(modal register)뿐 아니라 가성구(falsetto register)를 포함한 전체 음역대를 기록하였다. VRP 시행을 위한 보다 구체적인 절차 는 선행연구에 상세히 기술되어 있다(Lee, Choi, Lim, \& Lee, 2018; Lee \& Kim, 2019).

\section{자료분석}

CSL 메인 프로그램을 통해 녹음된 음성샘플은 다시 Real-time $\mathrm{EGG}$ 를 프로그램에서 로드 후 분석하여 평균 $\mathrm{SF}_{\mathrm{EGG}}(\mathrm{Hz})$ 를 측정 하였다. VRP 프로그램에서는 VRP 플롯과 SRP 플롯을 각각 로드
하여 분석함으로써 $\mathrm{Hz}$ 단위의 최고 음도( $\left.\mathrm{Max}_{\mathrm{VRP}}, \mathrm{Max}_{\mathrm{SRP}}\right)$ 와 최저 음도(Min $\left.{ }_{\mathrm{VRP}}, \mathrm{Min}_{\mathrm{SRP}}\right), \mathrm{Hz}$ 단위의 음역대(RangeVRP, RangesRP), 반음 단위의 음역대(Semi $i_{\mathrm{VRP}}, \mathrm{Semi}_{\mathrm{SRP}}$ )를 측정하였다. 이와 같은 VRP와 SRP 측정치를 Lee와 Kim (2019)의 회귀식에 대입하여 각각의 ESF0 $\left(\mathrm{ESF}_{\mathrm{VRP}}, \mathrm{ESF0} 0_{\mathrm{SRP}}\right)$ 를 계산하고, 두 $\mathrm{ESF} 0$ 와 $\mathrm{SF}_{\mathrm{EGG}}$ 간의 차이의 절 댓값 $\left(\Delta \mathrm{SF} 0_{\mathrm{VRP}}, \Delta \mathrm{SF} 0_{\mathrm{SRP}}\right)$ 과 두 가지 $\Delta \mathrm{SF} 0$ 의 합 $\left(\Delta \mathrm{SF} 0_{\mathrm{SUM}}\right)$ 또한 구하였 다. $\mathrm{ESF} 0$ 와 $\Delta \mathrm{SF} 0$ 를 산정하기 위한 회귀식과 계산식은 아래와 같다.

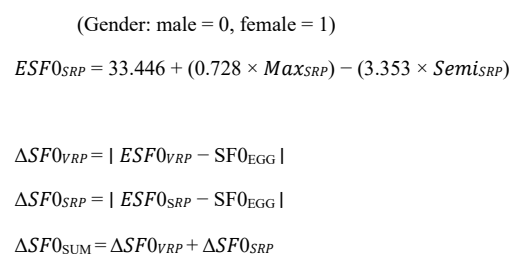

\section{통계분석}

통계분석 방법으로는 집단과 성별에 따른 $\mathrm{ESF} 0$ 값들과 $\Delta \mathrm{SF} 0$ 값 들의 비교를 위해 각각 이원 중다변량 분산분석(two-way MANO$\mathrm{VA})$ 을 시행하였다. 다음으로는 $\Delta \mathrm{SF}_{\mathrm{VRP}}, \Delta \mathrm{SF}_{\mathrm{SRP}}, \Delta \mathrm{SF}_{\mathrm{SUM}}$ 의 음성 장애 여부에 대한 진단적 능력을 확인하고 각 변수 간의 비교를 수 행하기 위하여 수신자 조작 특성 곡선(receiver operating characteristic curve, ROC curve) 분석을 시행하였으며, 각 변수별 곡선 아래 영역(area under curve, $\mathrm{AUC}$ )을 산정하고, $\triangle \mathrm{SF} 0_{\mathrm{VRP}}, \Delta \mathrm{SF} 0_{\mathrm{SRP}}$, $\triangle \mathrm{SF}_{\mathrm{SUM}}$ 간 $\mathrm{AUC}$ 의 비교를 하였다. $\mathrm{SF}_{\mathrm{EGG}}, \mathrm{ESF}_{\mathrm{VRP}}, \mathrm{ESF}_{\mathrm{SRP}}$ 간 상 관관계를 알아보기 위해 피어슨 상관분석을, $\Delta \mathrm{SF} 0_{\mathrm{VRP}}, \Delta \mathrm{SF} 0_{\mathrm{SRP}}$, $\Delta \mathrm{SF}_{\mathrm{SUM}}$ 과 $\mathrm{G}$ 척도 평정치 간의 상관관계를 알아보기 위하여 스피 어만 상관분석을 시행하였다. 이원 중다변량 분산분석과 상관분석 에는 SPSS 25.0 (IBM-SPSS Inc., Armonk, NY, USA) 프로그램을, $\mathrm{ROC}$ 곡선 분석과 AUC 간 비교에 있어서는 MedCalc 통계 소프트 웨어 버전 19.1.7을 이용하였으며, 유의수준은.05로 하였다.

\section{연구결과}

\section{집단과 성별에 따른 EGG, VRP, SRP 측정치}

집단과 성별에 따른 EGG, VRP, SRP 측정치의 기술통계가 Table 2에 제시되어 있다.

Table 3은 위의 측정치들을 이용하여 추정한 SF0와 $\Delta \mathrm{SF} 0$ 관련 변수들의 기술통계를 보여준다. 이 변수들을 집단 및 성별에 따라 비교한 결과, 집단(Wilk's Lambda $=.815, p<.001$ ), 성별(Wilk's $\mathrm{Lambda}=.118, p<.001$ ), 집단 $\times$ 성별 간 교호작용(Wilk's Lamb$\mathrm{da}=.829, p<.001)$ 이 모두 유의하였다. 구체적으로는 $\mathrm{ESFO}_{\mathrm{VRP}}$ 는 성 
Table 2. Descriptive statistics of electroglottographic, voice- and speech range profile measures

\begin{tabular}{|c|c|c|c|c|}
\hline \multirow{2}{*}{ Parameters } & \multicolumn{2}{|c|}{ Patient group ( $\mathrm{N}=85$ ) } & \multicolumn{2}{|c|}{ Normal group ( $\mathrm{N}=85$ ) } \\
\hline & Male $(\mathrm{N}=30)$ & Female (N=55) & Male $(\mathrm{N}=30)$ & Female $(\mathrm{N}=55)$ \\
\hline $\mathrm{SFO}_{\mathrm{EGG}}(\mathrm{Hz})$ & $133.530(23.861)$ & 186.715 (28.205) & $107.429(11.211)$ & $192.555(15.383)$ \\
\hline $\operatorname{MaXvRP}_{\text {VIz }}$ & 518.242 (203.320) & 637.110 (228.727) & 589.254 (153.920) & 755.536 (182.100) \\
\hline $\operatorname{Min}_{\text {VRP }}(H z)$ & $104.450(26.736)$ & 154.401 (57.76) & 83.706 (10.953) & 147.152 (18.091) \\
\hline Rangevrp $(\mathrm{Hz})$ & 414.632 (213.050) & 482.709 (240.677) & 505.547 (154.851) & 608.384 (185.237) \\
\hline Semivrp & $27.100(9.290)$ & 24.127 (8.300) & $33.233(5.740)$ & 27.909 (5.250) \\
\hline MaXsRP $(\mathrm{Hz})$ & 164.827 (35.987) & 245.650 (37.117) & 136.127 (19.563) & 250.378 (23.138) \\
\hline $\operatorname{Min}_{\text {SRP }}(\mathrm{Hz})$ & 117.469 (22.965) & 165.452 (43.289) & 89.879 (11.628) & 166.001 (16.715) \\
\hline Range $_{\text {SRP }}(\mathrm{Hz})$ & 47.359 (27.739) & 80.197 (38.852) & $46.248(16.421)$ & 84.378 (21.265) \\
\hline SemisRP & $5.767(2.921)$ & $7.236(4.176)$ & 7.167 (2.036) & $7.127(1.733)$ \\
\hline
\end{tabular}

Values are presented as mean (SD).

$\mathrm{SFO}_{\mathrm{EGG}}=$ speaking fundamental frequency measured by electroglottography; VRP=voice range profile; $\mathrm{SRP}=$ speech range profile; Max maximum pitch in $\mathrm{Hz}$; Min=minimum pitch in $\mathrm{Hz}$; Range = pitch range in $\mathrm{Hz}$; Semi = pitch range in semitones.

Table 3. Descriptive statistics of estimated SFO parameters and differences between estimated and measured SFO

\begin{tabular}{|c|c|c|c|c|}
\hline \multirow{2}{*}{ Parameters } & \multicolumn{2}{|c|}{ Patient group ( $\mathrm{N}=85$ ) } & \multicolumn{2}{|c|}{ Normal group $(\mathrm{N}=85)$} \\
\hline & Male $(\mathrm{N}=30)$ & Female $(\mathrm{N}=55)$ & Male $(\mathrm{N}=30)$ & Female $(\mathrm{N}=55$ \\
\hline $\mathrm{ESFOVRP}_{\mathrm{v}}(\mathrm{Hz})$ & $114.774(12.345)$ & $194.105(25.115)$ & $107.172(7.257)$ & 192.635 (9.191) \\
\hline $\mathrm{ESFO}_{\mathrm{SRP}}(\mathrm{Hz})$ & $134.105(22.176)$ & 188.015 (29.039) & $108.517(12.050)$ & 191.824 (15.061) \\
\hline $\mathrm{ESFO}_{\mathrm{SRP}}(\mathrm{Hz})$ & $22.202(14.627)$ & 16.548 (20.994) & 7.606 (6.078) & $9.750(7.141)$ \\
\hline$\Delta \mathrm{SFO}_{\mathrm{SRP}}(\mathrm{Hz})$ & $10.595(13.461)$ & 14.489 (13.788) & $5.945(4.799)$ & $6.767(5.252)$ \\
\hline$\Delta \mathrm{SFO}_{\text {Sum }}(\mathrm{Hz})$ & $32.797(22.352)$ & $23.777(24.080)$ & 13.550 (8.996) & $16.517(8.170)$ \\
\hline
\end{tabular}

Values are presented as mean (SD).

$\mathrm{ESFO}=$ estimated speaking fundamental frequency; $\triangle \mathrm{SFO}=$ differences between the $\mathrm{ESFO}$ and the $S F 0$ measured by electroglottography of a passage reading task; VRP= voice range profile; $S R P=$ speech range profile; $\triangle S F O_{\text {SUM }}=$ sum of the $\triangle S F O_{V R P}$ and $\triangle S F O_{S R P}$.

별 간 차이 $(F=.981, p<.001)$ 만 유의하였던 반면, $\mathrm{ESF}_{\mathrm{SRP}}$ 는 집단 $(F=10.022, p=.002)$, 성별 $(F=397.807, p<.001)$, 집단 $\times$ 성별 간 교 호작용 $(F=18.257, p<.001)$ 이 모두 유의하였다. 따라서 각 성별 집 단마다 환자-정상군 간 차이가 있는지 알아본 결과, 남성은 환자군 의 $\mathrm{ESF}_{\mathrm{SRP}}$ 가 정상군보다 유의하게 높았으나 $(t=-5.553, p<.001)$, 여성은 집단 간 차이가 유의하지 않았다 $(t=.863, p=.390) . \Delta \mathrm{SF}_{\mathrm{VRP}}$ $(F=21.801, p<.001), \Delta \mathrm{SF}_{\mathrm{SRP}}(F=13.950, p<.001)$, 그리고 $\Delta \mathrm{SF}_{\mathrm{SUM}}$ $(F=24.746, p<.001)$ 의 경우 환자군이 정상군에 비해 유의하게 더 큰 것으로 나타났다.

$\mathrm{EGG}$ 를 통해 측정한 $\mathrm{SF}$ 와 추정된 기본주파수들 간에 상관관 계가 있는지 살펴 본 결과, $\mathrm{SF}_{\mathrm{EGG}}$ 는 $\mathrm{ESF}_{\mathrm{VRP}}(r=.881, p<.001), \mathrm{ES}-$ $\mathrm{F}_{\mathrm{SRP}}(r=.933, p<.001)$ 와 강한 양의 상관관계를 보였다(Table 4). $\mathrm{G}$ 평정치는 $\Delta \mathrm{SF}_{\mathrm{VRP}}(\mathrm{rho}=.338, p<.001), \Delta \mathrm{SF}_{\mathrm{SRP}}(\mathrm{rho}=.299, p<$ $.001), \Delta \mathrm{SF}_{\mathrm{SUM}}(\mathrm{rho}=.466, p<.001)$ 과 약한 양의 상관관계를 보였 다(Table 5).

세 가지의 $\triangle \mathrm{SF} 0$ 가 음성장애에 대한 선별검사 도구로서의 유용 성을 가지고 있는지 알아보기 위해 ROC 곡선 분석을 시행한 결과
Table 4. Correlation matrix of the $\mathrm{SFO}_{\mathrm{EGG}}$ and $\mathrm{SFO}$ estimated by voice and speech range profiles

\begin{tabular}{lccc}
\hline Parameters & SFOEGG $_{\text {EG }}$ & ESFO & ESFP \\
\hline SFOEGG & 1 & $.881^{* * *}$ & $.933^{* * *}$ \\
ESFOVRP & $.881^{* * *}$ & 1 & $.910^{* * *}$ \\
ESFOSRP & $.933^{* * *}$ & $.910^{* * *}$ & 1
\end{tabular}

$\mathrm{SFO}_{\mathrm{EGG}}=$ speaking fundamental frequency measured by electroglottography; VRP= voice range profile; $\mathrm{SRP}=$ speech range profile.

${ }^{* * *} p<.001$

Table 5. Correlation matrix of the $\mathrm{G}$ scale and $\triangle \mathrm{SFO}$ measures

\begin{tabular}{lcccc}
\hline Parameters & $\mathrm{G}$ & $\Delta \mathrm{SFO}_{\mathrm{VRP}}$ & $\Delta \mathrm{SFO}_{\text {SRP }}$ & $\Delta \mathrm{SFO}_{\text {SUM }}$ \\
\hline $\mathrm{G}$ & 1 & $.338^{* * *}$ & $.299^{* * *}$ & $.466^{* * *}$ \\
$\Delta$ SFO $_{\text {VRP }}$ & $.338^{* * *}$ & 1 & .028 & $.758^{* * *}$ \\
$\Delta \mathrm{SFO}_{\text {SRP }}$ & $.299^{* * *}$ & .028 & 1 & $.588^{* * *}$ \\
$\Delta$ SFO $_{\text {Sum }}$ & $.466^{* * *}$ & $.758^{* * *}$ & $.588^{* * *}$ & 1 \\
\hline
\end{tabular}

$\mathrm{G}=$ Grade of the GRBAS scale; $\mathrm{ESFO}=$ estimated speaking fundamental frequency; $\triangle \mathrm{SFO}=$ differences between the ESFO and the SFO measured by electroglottography of a passage reading task; $V R P=$ voice range profile; $S R P=$ speech range profile;

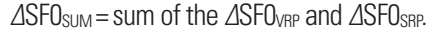
${ }^{* * *} p<.001$. 
Table 6. Comparison of clinical usefulness as a screening tool between the $\triangle$ SFO measures

\begin{tabular}{|c|c|c|c|c|c|c|c|c|}
\hline Parameters & AUC & $95 \% \mathrm{Cl}$ & $z$ & $p$ & Cut-off score & Youden index J & Sensitivity & Specificity \\
\hline$\triangle \mathrm{SFOVRP}$ & .690 & $.615-.759$ & 4.700 & $<.001$ & $>10.867$ & 0.329 & 65.88 & 67.06 \\
\hline$\triangle \mathrm{SFO}_{\mathrm{SRP}}$ & .673 & $.597-.742$ & 4.223 & $<.001$ & $>10.348$ & 0.306 & 51.76 & 78.82 \\
\hline$\triangle \mathrm{SFO}_{\text {SUM }}$ & .771 & $.700-.832$ & 7.664 & $<.001$ & $>17.777$ & 0.424 & 75.29 & 67.06 \\
\hline
\end{tabular}

ESFO = estimated speaking fundamental frequency; $\triangle \mathrm{SFO}=$ differences between the ESFO and the $S F 0$ measured by electroglottography of a passage reading task; $V R P=$ voice range profile; $\mathrm{SRP}=$ speech range profile; $\triangle \mathrm{SFO}$ sum $=$ sum of the $\triangle \mathrm{SFO}$ vRP and $\triangle \mathrm{SFO}$ SRP.

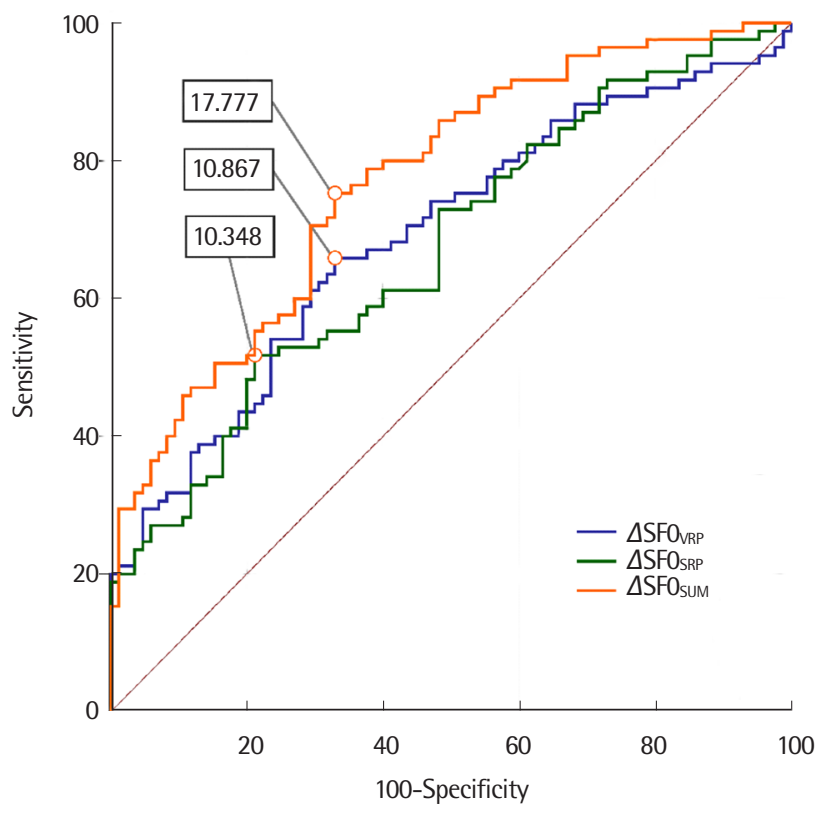

Figure 1. Receiver operating characteristic (ROC) curve of the $\triangle \mathrm{SFO}$ measures. ESFO = estimated speaking fundamental frequency; $\triangle S F O=$ differences between the ESFO and the SFO measured by electroglottography of a passage reading task; $\mathrm{VRP}=$ voice range profile; $\mathrm{SRP}=$ speech range profile; $\triangle \mathrm{SFO}$ sum $=$ sum of the $\triangle \mathrm{SFO}$ vrp and $\triangle \mathrm{SFO}$ sRP.

가 Table 6 과 Figure 1 에 제시되어 있다. $\Delta \mathrm{SF}_{\mathrm{VRP}}, \Delta \mathrm{SF} 0_{\mathrm{SRP}}, \Delta \mathrm{SF}_{\mathrm{SUM}}$ 의 AUC는 각각 .690, .673, .771이었으며, 환자군과 정상군을 구분 하는 기준점은 각각 $10.867,10.348,17.777$ 이었다. ROC 곡선 간 비 교를 수행한 결과, $\Delta \mathrm{SF}_{\mathrm{SUM}}$ 의 $\mathrm{AUC}$ 가 $\Delta \mathrm{SF} 0_{\mathrm{VRP}}(z=2.780, p=.005)$, $\Delta \mathrm{SF}_{\mathrm{SRP}}(z=2.560, p=.011)$ 의 $\mathrm{AUC}$ 보다 유의하게 컸으며, $\Delta \mathrm{SF} 0_{\mathrm{VRP}}$, $\Delta \mathrm{SF} 0_{\mathrm{SRP}}$ 간 차이는 유의하지 않았다 $(z=0.316, p=.752)$.

\section{논의 및 결론}

이 연구에서는 EGG와 VRP, SRP의 객관적 측정치들을 함께 활 용하여 유도된 지표인 $\triangle \mathrm{SF} 0$ 의 임상적 유용성을 탐색하였다. 음성 장애 환자군과 정상군 집단과 성별에 따라 추정된 $\mathrm{SF} 0$ 와 $\Delta \mathrm{SF} 0$ 에 있어 차이가 있는지 확인한 결과, $\mathrm{SRP}$ 의 추정 $\mathrm{SF} 0$ 는 남성에서만 환
자-정상군 간 차이가 있었고, 세 가지의 $\Delta \mathrm{SF} 0$ 모두 환자군의 측정 치가 정상군보다 더 높았다. 아울러 $\mathrm{EGG}$ 의 SF0와 VRP, SRP로 추 정한 $\mathrm{SF} 0$ 간 강한 양의 상관관계, 그리고 세 $\triangle \mathrm{SF}$ 와 $\mathrm{G}$ 평정치 간 약 한 상관관계가 있었다. 마지막으로 음성장애에 대한 선별검사 도구 로서의 유용성을 살펴 본 결과, $\mathrm{VRP}$ 와 $\mathrm{SRP}$ 의 추정 SF0와 EGG의 $\mathrm{SF} 0$ 간 차이를 합한 $\triangle \mathrm{SF} 0_{\mathrm{sum}}$ 의 $\mathrm{AUC}$ 가 양호(acceptable)한 수준인 것을 확인하였다. 이와 같은 결과들을 통해 볼 때, $\triangle \mathrm{SF}$ 라고 하는 지표는 음성장애 선별검사 도구로서의 유용성을 보여주었다고 할 수 있다.

$\mathrm{VRP}$ 와 SRP로 추정한 ESF0는 모두 성별 간 차이가 유의하였다. 이는 정상 집단에서 $\mathrm{ESF} 0$ 의 성별 간 차이를 보고한 Lee와 Kim (2019)의 연구결과와 일치하며, ESF0가 성별에 따른 SF0의 차이를 잘 반영함을 보여준다. 그런데 $\mathrm{VRP}$ 로 추정한 $\mathrm{ESF} 0$ 는 환자-정상군 간 차이가 유의하지 않았던 반면, SRP로 추정한 ESF0의 경우 남성 은 환자군이 정상군보다 유의하게 높았으나, 여성은 집단 간 차이 가 유의하지 않았다. 이는 다음의 세 가지 요인이 작용한 결과로 보 인다. 첫째, 부분적으로 본 연구에 포함된 환자군의 특성에 기인하 는 것으로 본다. 가령 성대 구증(sulcus vocalis)이나 성대 반흔(vocal fold scarring) 등과 같은 질환군이 다수 포함되었는데, 이러한 질환의 경우 최저 음도가 심각하게 제한되는 대신 전반적인 음도 범위가 상향되는 경우가 많다. 이와 함께 둘째로 VRP와 SRP 간에 $\mathrm{SF} 0$ 를 추정하는 회귀식에 포함된 변수의 차이가 상호작용하였을 것으로 여겨진다. 즉 $\mathrm{ESF}_{\mathrm{VRP}}$ 는 남성에 비해 여성의 $\mathrm{ESF} 0$ 가 높도록 성별이 변수로 포함되어 있고 VRP 음도의 최저값이 포함된 반면, $\mathrm{ESF}_{\mathrm{SRP}}$ 의 경우 성별이 변인으로 포함되지 않는 대신 $\mathrm{SRP}$ 의 최대 음도가 포함된다. 본 연구의 결과 중 남성에서 다른 측정치와 가장 두드러진 차이를 보인 측정치는 환자군의 SRP의 ESF0 (134.105士 $22.176 \mathrm{~Hz}$ )였으며, 이는 특히 남성 환자군의 음성장애에 따른 음역 대의 변화가 VRP보다는 SRP에서 더 잘 반영된다는 점을 시사하 는 것으로도 해석할 수 있는 부분이다. 셋째로는 VRP와 SRP 과제 의 특성이 반영된 것으로 본다. 즉 환자군에서 ESF0의 집단 간 유 의한 차이를 알아보기에는 VRP보다는 SRP가 더 민감하게 차이를 보여줄수 있다고 볼수 있다. 
세 가지 $\triangle \mathrm{SF} 0$ 의 경우 환자군이 정상군에 비해 더 높은 수치를 보 였다. 이는 정상군에 대한 선행연구에서는 알 수 없었던 부분이며, 음향학적 음도 측정치를 기반으로 예측한 SF0와 EGG의 SF0 간의 간극이 큰 것이 음성장애의 중요한 특징으로 간주될 수 있는 가능 성을 보여준 것이라 하겠다. 특히 정상적인 음도 범위를 벗어난 특 징을 보이는 음성장애 집단을 감별하거나 특성을 기술하고, 치료 전후 진전 정도를 객관적으로 파악할 뿐만 아니라, 환자에게 바람 직한 SF0 수준을 제시하는 데 활용될 가능성을 제시한다는 점에 서 의의가 있다고 본다. 다만 본 연구의 결과는 음역대 중 주파수에 관한 결과에 국한된 것으로서 강도에 대한 연구는 별도의 연구에 서 추가적으로 이루어져야 할 필요가 있다고 생각된다.

예컨대 본인의 구조상 낼 수 있는 적절한 음역대에 비해 다소 낮 은 음도로 발화함으로써 성대의 과기능을 유발하는 접촉성 육아 종(contact granuloma)의 경우, 본인의 최소 혹은 최대 음도나 그 범위를 기반으로 하여 볼 때 $120 \mathrm{~Hz}$ 정도의 SF0가 바람직해 보임에 도 불구하고, 본인의 개인적인 선호에 따라 그보다 낮은 $100 \mathrm{~Hz}$ 정 도의 평균 $\mathrm{SF} 0$ 으로 발화하여 계속적인 성대 과기능을 유발하고, 이로 인해 접촉성 육아종이 야기된다면 이에 대해 바람직한 음도 를 확립하고자 할 때 객관적인 목표 SF0와 그 근거를 제시할 수 있 다는 것이다. 현재까지는 음성 치료 시 음도의 재확립을 수행할 때 '바람직한' 음도를 가늠할 때 정상 성인의 규준 자료만을 참고하였 지만, 이러한 개인에 따른 객관적인 데이터를 참고한다면 보다 객관 적인 방식으로 치료가 이루어져 음성장애 분야에서의 환자 맞춤형 치료(personalized medicine)에 기여할 수 있을 것이다. 아울러 환 자 본인에게 치료의 근거나 기준 등에 대한 정보를 사전에 정확하 게 알려주고, 치료의 위험이나 이득에 대한 정보를 주는 근거 제공 실무(evidence-informed practice)를 수행할 때 환자가 중재의 목 표로서 쉽게 이해하는데 도움을 주고 일반화를 촉진할 수 있는 하 나의 가이드가 될 수 있을 것으로 본다. 따라서 이와 같은 점을 활 용하여 $\triangle \mathrm{SF} 0$ 를 가이드로 삼았을 때와 그렇지 않았을 때, 중재 효 과의 차이나 환자의 만족도 차이를 알아보는 후속 연구가 가능할 것으로 생각된다.

$\mathrm{EGG}$ 의 $\mathrm{SF} 0$ 와 추정된 $\mathrm{ESF} 0$ 간 상관관계를 알아 본 결과, 강한 양 의 상관관계를 보였다. 이는 역시 VRP $(r=.873), \mathrm{SRP}(r=.932)$ 를 통해 예측된 ESF0와 강한 상관관계를 보고한 Lee와 Kim (2019)의 연구결과와 일치하며, 음역대의 음도 관련 측정치들을 토대로 대상 자의 평상 시 $\mathrm{SF} 0$ 를 예측할 수 있다는 결과와 일맥상통한다고 할 수 있다. 또한 이러한 상관관계가 환자군의 자료에도 적용될 수 있 다는 것을 확인하였다는 데에서 그 의의를 찾을 수 있다. 다만 $\mathrm{G}$ 평 정치는 세 가지 $\triangle \mathrm{SF} 0$ 와 공통적으로 약한 양의 상관관계를 보였다.
이는 본 연구의 중심이 된 $\Delta \mathrm{SF}$ 가 전반적 중증도 척도와는 별개로 발성 능력을 나타내는 보조적인 지표로서 사용되어야 함을 시사한 다고볼수있다.

$\mathrm{ROC}$ 곡선 분석을 시행한 결과 $\Delta \mathrm{SF} 0_{\mathrm{VRP}}, \Delta \mathrm{SF} 0_{\mathrm{SRP}}, \Delta \mathrm{SF} 0_{\mathrm{SUM}}$ 의 $\mathrm{AUC}$ 는 각각 $.690, .673, .771$ 로 $\Delta \mathrm{SF} 0_{\mathrm{SUM}}$ 의 $\mathrm{AUC}$ 가 양호한 수준이 었으며, $\mathrm{VRP}$ 와 SRP의 $\triangle \mathrm{SF}$ 보다 유의하게 큰 $\mathrm{AUC}$ 를 보였다. 이러한 결과는 선행연구에서 단순히 정상치를 제시한 것을 넘어 $\Delta \mathrm{SF}_{\mathrm{sum}}$ 이 음성장애에 대한 선별 검사로 유용하게 이용될 수 있는 가능성 을 제시하였다는 것을 보여준다. 또 다른 한편으로 VRP와 SRP의 $\triangle \mathrm{SF} 0$ 를 합산한 $\Delta \mathrm{SF}_{\mathrm{Sum}}$ 의 유용성이 개별지표보다 더 컸다는 것은 음역대를 검사함에 있어 단순히 모음 발성을 이용한 검사뿐 아니 라 말 자료를 이용한 음역대 검사를 함께 병행하여야 할 필요성을 일부 뒷받침해주는 결과라고도 할 수 있을 것이다. 다만 $\Delta \mathrm{SF} 0_{\mathrm{Sum}}$ 이 실제 임상에서 활발하게 선별검사 도구로 활용되기 위해서는 시간 적 효율성을 높이기 위한 추가 연구가 필요할 것으로 여겨지며, 그 러한 연구가 진행되기 전까지는 음역대에 문제가 있는 환자에 대한 심화 검사(deep test)로서의 활용도는 높을 것으로 판단된다.

다만 본 연구에서는 아쉽게도 질환군에 따른 특성의 차이를 살 펴보지는 못하였으며, 특히 정상에 비해 음도가 상승하거나 하강 하는 경향을 뚜렷하게 보이는 질환군을 구분하여 $\triangle \mathrm{SF} 0$ 의 특성을 규명하지는 못하였다. 또한 $\Delta \mathrm{SF} 0$ 를 통해 살펴볼 수 있는 SF0상의 차이가 주관적인 음성장애 정도, 더 구체적으로는 직업적 음성사 용자나 일반인의 음성 활동 및 참여 프로파일과 갖는 상관관계에 대해서는 자세히 규명하지 못하였다는 한계가 명확하므로, 이를 고 려한 후속 연구가 필요할 것으로 여겨진다. 아울러 이 연구는 어디 까지나 $\triangle \mathrm{SF} 0$ 가 음성장애에 대한 선별검사 도구로서 사용될 수 있 는 가능성을 일부 확인하였다는 데 의의가 있는 것이며, 이를 진단 의 도구로 섣불리 확대하여 사용하는 일은 매우 위험할 수 있으므 로 주의가 필요하다고 여겨진다. 요약하자면 $\triangle \mathrm{SF} 0$ 는 음성장애 선 별검사를 위한 객관적인 지표의 하나로서 사용될 수 있다고 여겨 지며, 이는 VRP와 SRP의 임상적 가치를 제고하는데 도움을 줄 것 으로 여겨진다.

\section{REFERENCES}

Awan, S. N., Roy, N., \& Cohen, S. M. (2014). Exploring the relationship between spectral and cepstral measures of voice and the Voice Handicap In$\operatorname{dex}$ (VHI). Journal of Voice, 28(4), 430-439.

Berg, M., Fuchs, M., Wirkner, K., Loeffler, M., Engel, C., \& Bergerm, T. (2017). The speaking voice in general population: normative data and associations 
to sociodemographic and lifestyle factors. Journal of Voice, 31(2), e13-257. e24.

D’Alatri, L., \& Marchese, M. R. (2014). The speech range profile (SRP): an easy and useful tool to assess vocal limits. Acta Otorhinolaryngologica Italica, 34(4), 253-258.

dos Santos, A. C. M., de Menezes Borrego, M. C., \& Behlau, M. (2015). Effect of direct and indirect voice training in speech-language pathology and audiology students. CoDAS, 27(4), 384-391.

Hirano, M. (1981). Clinical examination of voice. New York, NY: Springer.

Jung, W. J., Choi, S. H., \& Choi, C. H. (2019). Development and validation of a novel simplified voice range profile measurement method: comparison of maximum vocal performance based on the VRP protocol. Communication Sciences \& Disorders, 24(3), 770-784.

Kim, H. (2012). Neurologic speech-language disorders. Seoul: Sigma Press.

Kim, J., \& Lee, S. J. (2019). Development and validation of Speech Range Profile task. Phonetics and Speech Sciences, 11(3), 77-87.

Kim, S. T., Jeong, G. E., Kim, S. Y., Choi, S. H., Lim, G. C., Han, J. H., \& Nam, S. Y. (2009). The effect of voice therapy in vocal polyp patients. Phonetics and Speech Sciences, 1(2), 43-49.

Lee, S. J., Choi, H. S., Kim, H., Byeon, H. K., Lim, S. E., \& Yang, M. K. (2016). Korean Version of the Voice Activity and Participation Profile (K-VAPP): a validation study. Communication Sciences \& Disorders, 21(4), 695-708.

Lee, S. J., Choi, H. S., Lim, J. Y., \& Lee, K. Y. (2018). The effect of the Modified Voiced Lip Trill (MVoLT) training on vocal changes of musical theater students. Phonetics and Speech Sciences, 10(4), 135-146.

Lee, S. J., \& Kim, J. (2019). Prediction of speaking fundamental frequency using the voice and speech range profiles in normal adults. Phonetics and Speech Sciences, 11(3), 49-55.

Ma, E. P., Robertson, J., Radford, C., Vagne, S., El-Halabi, R., \& Yiu, E. (2007). Reliability of speaking and maximum voice range measures in screening for dysphonia. Journal of Voice, 21(4), 397-406.

Ma, E. P., \& Yiu, E. M. (2006). Multiparametric evaluation of dysphonic severity. Journal of Voice, 20(3), 380-390.

Ma, E. P., \& Yiu, E. (2011). Handbook of voice assessments. San Diego, CA: Plural Publishing.

Mailänder, E., Mühre, L., \& Barsties, B. (2017). Lax Vox as a voice training program for teachers: a pilot study. Journal of Voice, 31(2), 262.e13-262. $\mathrm{e} 22$.

Meerschman, I., D’haeseleer, E., Catry, T., Ruigrok, B., Claeys, S., \& Van Lierde, K. (2017). Effect of two isolated vocal facilitating techniques glottal fry and yawn-sigh on the phonation of female speech-language pathology students: a pilot study. Journal of Communication Disorders, 66, 40-50.

Patel, R. R., Awan, S. N., Barkmeier-Kraemer, J., Courey, M., Deliyski, D., Eadie, T., Paul, D., Švec, J. G., \& Hillman, R. (2018). Recommended protocols for instrumental assessment of voice: American Speech-LanguageHearing Association expert panel to develop a protocol for instrumental assessment of vocal function. American Journal of Speech-Language Pathology, 27(3), 887-905.

Sataloff, R. T. (2005). Clinical assessment of voice. San Diego: Plural Pub.

Sanchez, K., Oates, J., Dacakis, G., \& Holmberg, E. B. (2014). Speech and voice range profiles of adults with untrained normal voices: methodological implications. Logopedics Phoniatrics Vocology, 39(2), 62-71.

Siupsinskiene, N., \& Lycke, H. (2011). Effects of vocal training on singing and speaking voice characteristics in vocally healthy adults and children based on choral and nonchoral data. Journal of Voice, 25(4), e177-e189.

Wuyts, F. L., De Bodt, M. S., Molenberghs, G., Remacle, M., Hyelen, L., Millet B., Van Lierde, ..., Van de Heyning, P. (2000). The dysphonia severity index: an objective measure of vocal quality based on a multiparameter approach. Journal of Speech, Language, and Hearing Research, 43(3), 796809. 


\section{국문초록}

\section{음성장애 환자에서 음성 및 말 범위 프로파일을 이용한 추정 발화 기본주파수의 임상적 유용성} 이승진 ${ }^{\prime 2} \cdot$ 김재옥 ${ }^{3}$

1연세대학교 의과대학 이비인후과학교실, ${ }^{2 ㄱ ㅏ ㅇ ㄴ ㅏ ㅁ ㅅ ㅔ ㅂ ㅡ ㄹ ㅏ ㄴ ㅅ ㅡ ㅂ ㅕ ㅇ ㅇ ㅝ ㄴ ~ ㅇ ㅣ ㅂ ㅣ ㅇ ㅣ ㄴ ㅎ ㅜ ㄱ ㅘ ~ ㅎ ㅜ ㄷ ㅜ ㅇ ㅡ ㅁ ㅅ ㅓ ㅇ ㅇ ㅓ ㄴ ㅇ ㅓ ㅇ ㅢ ㅎ ㅏ ㄱ ㅇ ㅕ ㄴ ㄱ ㅜ ㅅ ㅗ, ~}{ }^{3}$ 강남대학교 교육대학원 언어치료교육전공

배경 및 목적: 본 연구에서는 음성장애 환자군과 정상군 집단과 성별에 따라 음성 및 말 범위 프로파일(VRP, SRP)을 이용한추정 발화 기본주파수(ESF)와 전기성문파형검사로 측정한 $\mathrm{SF} 0 \mathrm{EGG}$ 간 차이인 발화 기본주파수 차이 $\left(\Delta \mathrm{SF} 0_{\mathrm{VRP}}, \Delta \mathrm{SF} 0_{\mathrm{SRP}}, \Delta \mathrm{SF} 0_{\mathrm{sum}}\right)$ 가 서로 다른 지 확인하고자 하였다. 또한 $\mathrm{SF}_{\mathrm{EGG}}, \mathrm{ESF}_{\mathrm{VRP}}, \mathrm{ESF}_{\mathrm{SRP}}$ 간 상관관계, 그리고 세 $\triangle \mathrm{SF} 0$ 와 전반적 중증도 평정치 간 상관관계를 알아보았다. 마지막으로 $\triangle \mathrm{SF} 0$ 의 음성장애 선별검사 도구로서의 유용성 및 환자군과 정상군 간의 구분을 위한 기준점을 확인하고자 하였다. 방법: 음성장애 환자군와 정상군 각 85 명(남 30 명, 여 55 명)을 대상으로 문단 읽기 과제 시의 평균 $\mathrm{SFO}_{\mathrm{EGG}}$ 를 측정하였다. 또한 $\mathrm{VRP}$ 와 $\mathrm{SRP}$ 를 시행하여 최고 음도와 최저 음도, $\mathrm{Hz}$ 단위의 음역대, 반음 단위의 음역대를 측정하였다. 이를 Lee \& Kim (2019)의 회귀식에 대입하여 각 각의 $\mathrm{ESF} 0\left(\mathrm{ESF}_{\mathrm{VRP}}, \mathrm{ESF} 0_{\mathrm{SRP}}\right)$ 를 계산하고, 발화 기본주파수차이, 즉 두 $\mathrm{ESF} 0$ 와 $\mathrm{SF}_{\mathrm{EGG}}$ 간의 차이의 절댓값 $\left(\Delta \mathrm{SF} 0_{\mathrm{VRP}}, \Delta \mathrm{SF} 0_{\mathrm{SRP}}\right)$ 과 두 $\Delta \mathrm{SF} 0$ 의 합 $\left(\Delta \mathrm{SFO}_{\mathrm{SUM}}\right)$ 또한 구하였다. 결과: $\mathrm{ESF}_{\mathrm{SRP}}$ 는 남성에서만 환자-정상군 간 차이가 있었고, 환자군의 $\Delta \mathrm{SF} 0$ 가 정상군보다 더 높았다. $\mathrm{SF}_{\mathrm{EGG}}, \mathrm{ESF}_{\mathrm{VRP}}, \mathrm{ESF}_{\mathrm{SRP}}$ 간 강한 양의 상관관계, 그리고 세 $\Delta \mathrm{SF} 0$ 와 $\mathrm{G}$ 평정치 간 약한 상관관계가 나타났다. $\Delta \mathrm{SF}_{\mathrm{VRP}}, \Delta \mathrm{SF}_{\mathrm{SRP}} \Delta \mathrm{SF}_{\mathrm{SUM}}$ 의 $\mathrm{AUC}$ 는 각각 $.690, .673, .771$ 이었으며, 기준점은 각각 $10.867,10.347,17.777$ 이었다. $\Delta \mathrm{SF}_{\mathrm{sUM}}$ 의 $\mathrm{AUC}$ 가 $\Delta \mathrm{SF}_{\mathrm{VRP}}, \Delta \mathrm{SF}_{\mathrm{SRP}}$ 의 $\mathrm{AUC}$ 보다 유의하게 컸다. 논의 및 결론: 본 연구의 결과는 $\Delta \mathrm{SF} 0$ 가 음성장애 선별검사를 위한 객관적인 지표의 하나로서 사용될 수 있는 가능성 을 보여주었으며, 이는 VRP와SRP의 임상적 가치를 제고하는 데 도움을 줄 것으로 여겨진다.

핵심어: 음성장애, 추정 발화 기본주파수(ESFO), 발화 기본주파수 차이( $\triangle \mathrm{SFO}$ ), 음성 범위 프로파일(VRP), 말 범위 프로파일(SRP)

본 연구는 2018년 대한민국 교육부와 한국연구재단의 지원을 받아수행된 연구임(NRF-2018S1A5A2A03032902).

\section{참고문헌}

김성태, 정고은, 김상윤, 최승호, 임길채, 한주희, 남순열(2009). 성대용종 환자의 음성치료 효과. 말소리와음성과학, 1(2), 43-49. 김재옥, 이승진(2019). 발화범위 프로파일 과제 개발 및 타당성 검증. 말소리와음성과학, 11(3), 77-87.

김향희(2012). 신경언어장애. 서울: 시그마프레스.

정원정, 최성희, 최철희(2019). 새로운 축약된 음성범위프로파일 검사법 개발과 타당도 VRP 프로토콜에 따른 최대 발성 수행력 비교. Communication Sciences \& Disorders, 24(3), 770-784.

이승진, 김재옥(2019). 정상 성인에서 음성 및 말소리 범위 프로파일을 이용한 발화 기본주파수 예측 말소리와 음성과학, 11(3), 49-55. 이승진, 최홍식, 김향희, 변형권, 임성은, 양민교(2016). 음성 활동 및 참여 프로파일-한국판(K-VAPP): 타당성 검증 연구. Communication Sciences \&

Disorders, 21(4), 695-708.

이승진, 최홍식, 임재열, 이광용(2018). 응용 입술트릴 훈련이 뮤지컬 전공 학생의 음성 변화에 미치는 효과. 말소리와음성과학, 10(4), 135-146.

\section{ORCID}

이승진(제1저자, 교신저자, 연구조교수 https://orcid.org/0000-0001-6200-0004); 김재옥(공동저자, 교수 https://orcid.org/0000-0002-6504-7294) 